\title{
Expression of p53 protein in pituitary adenomas
}

M.C. Oliveira ${ }^{1}$, C.P. Marroni ${ }^{1}$, C.B. Pizarroㅁ, J.F. Pereira-Lima ${ }^{1}$, L.M. Barbosa-Coutinho ${ }^{2}$ and N.P. Ferreira ${ }^{3}$

\section{Correspondence}

M.C. Oliveira

Dona Mimi Moro, 40

90480-050 Porto Alegre, RS

Brasil

Fax: + 51-328-6761

E-mail: mco@ portoweb.com.br

Received April 27, 2001

Accepted March 8, 2002
Departamentos de ${ }^{1}$ Endocrinologia, ${ }^{2}$ Patologia and ${ }^{3} \mathrm{~N}$ eurocirurgia, Fundação Faculdade Federal de Ciências Médicas de

Porto Alegre e Irmandade Santa Casa de Misericórdia de Porto Alegre, Porto Alegre, RS, Brasil

\section{Abstract}

Inactivating mutations of TP53, a tumor suppressor gene, are associated with abnormal cell proliferation. Although p53 expression is common in many human malignancies, p53 protein has seldom been evaluated in pituitary tumors. When detected, the percentage of p53positive cells is low, and, in general, it is exclusive for invasive lesions. The aim of the present study was to use immunohistochemistry to determine the presence of $\mathrm{p} 53$ protein in pituitary adenomas from tumor samples of 163 surgeries performed in 148 patients $(40 \%$ male, $60 \%$ female). In $35 \%$ of the cases the adenoma was nonfunctional, while in the others it was associated with PRL, GH and/or $\mathrm{ACTH}$ endocrine hypersecretion syndrome. Macroadenomas were observed in $83.2 \%$ of the cases with available neuroimage evaluation, of which $28 \%$ invaded the cavernous, sphenoid and/or ethmoidal sinus, bone, third ventricle or subfrontal lobe. p53 protein was detected in $2 / 148$ patients $(1.3 \%)$. Immunohistochemistry was positive for PRL and GH in these cases. Due to the high percentage of invasive pituitary adenomas found in our study, the low frequency of p53 detection suggests that it is inadequate as a routine marker for aggressiveness and as a predictive factor of tumor behavior.

\author{
Key words \\ - Pituitary \\ - Pituitary adenoma \\ - Invasive adenoma \\ - p53 \\ - Immunohistochemistry
}

Pituitary adenomas are frequent, being diagnosed in about $27 \%$ of glands examined in autopsies (1) and incidentally in about $20 \%$ of imaging scans of the sellar area (2). More uncommon are the adenomas diagnosed clinically because of either their association with endocrine clinical syndromes or symptoms resulting from the presence of a tumor mass.

Pituitary tumorigenesis has classically involved the hypothalamic theory and the pituitary intrinsic defect, the latter involving clonality, activation of oncogenes and inactivation of tumor suppressor genes. Both theories are possibly operant, the process starting from transformed cells, whose progression depends on hormonal stimuli and other growth factors (3).

TP53, a tumor suppressor gene located on chromosome 17, encodes a protein that exerts antiproliferative effects such as inhibition of cell growth by inhibiting the G1-S transition of the cell cycle. It is postulated that the p53 protein also induces apoptosis. In normal cells, p53 is present at very low levels, which are undetectable by immunohistochemistry. Its mutant forms, however, have a longer half-life and are more stable than the original form and accumulate in the nucleus, being promptly detected by immu- 
nohistochemistry (4). Inactivating mutations of TP53 are among the most frequent alterations in human neoplasias, but they seldom have been evaluated in pituitary tumors. While some investigators did not detect p53 expression in pituitary adenomas $(5,6)$, others reported it in invasive $(7,8)$ and noninvasive adenomas (9).

The present investigation was designed to determine the presence of p53 in human pituitary adenomas of different hormonal phenotypes.

Tissue from surgeries performed on 148 patients was used. Patients had undergone resection of pituitary tumors at a reference neurosurgery hospital in southern Brazil. The medical records of these patients were reviewed for clinical presentation, hormonal evaluation, pituitary image and surgical reintervention. Tumors were considered as microadenomas when they were less than 10 $\mathrm{mm}$ in size, and as macroadenomas when they were $10 \mathrm{~mm}$ or larger, regardless of the presence of suprasellar extension. Invasive adenomas were those which showed invasion of the cavernous, sphenoid or ethmoidal sinus, bone, third ventricle or subfrontal lobe. Recurrent tumors were those in which a new tumor growth resulted in another sur-

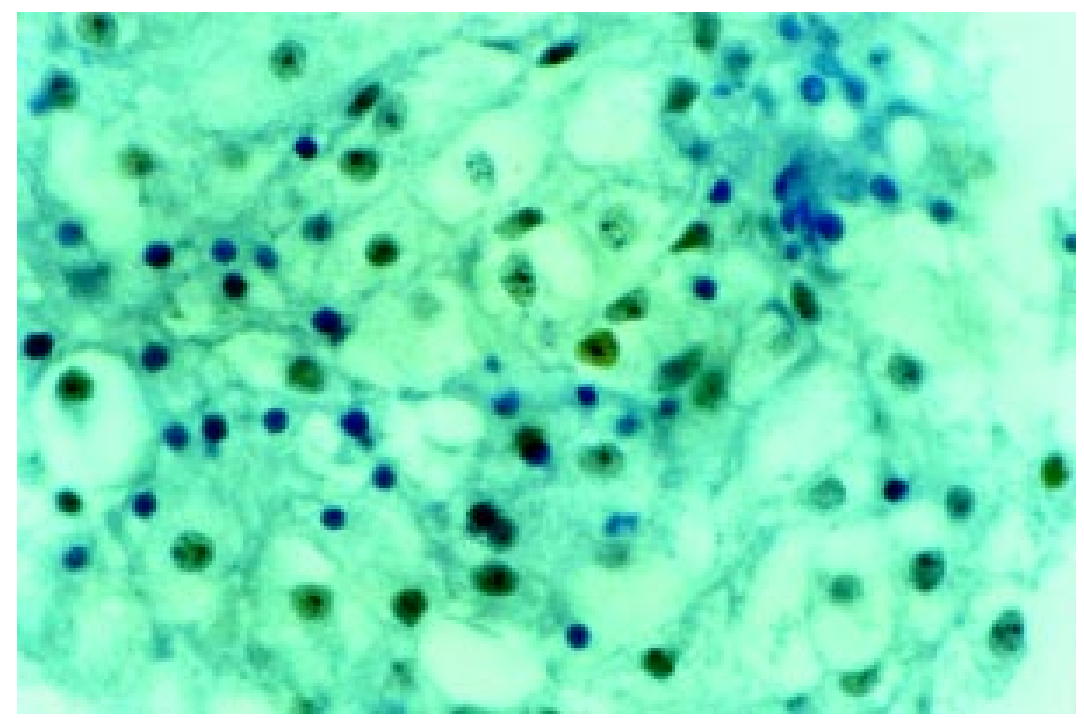

Figure 1. p53 Immunoreactivity (brown nuclei) in adenomatous tissue from one of the cases. gical resection.

Samples embedded in paraffin, stored in a bank of adenomatous pituitary tissue, were cut and sections were mounted on glass slides prepared with organosilane. The immunohistochemical study was based on the streptavidin-biotin immunoperoxidase method (Strept ABComplex/HRP, Dako A/S, Glostrup, Denmark). Briefly, the sections were submitted to deparaffinization, rehydration, blockade of endogenous peroxidase activity, antigen retrieval, and incubation with sodium citrate, and were then placed in a microwave oven for $10 \mathrm{~min}$ at maximum potency and for $10 \mathrm{~min}$ at medium potency. The primary antibody used for detection of $\mathrm{p} 53$, at 1:50 dilution, was the mouse monoclonal antibody (Dako) that recognizes an epitope at the N-terminus of the human p53 protein and reacts with both the wild type and mutant type of the protein. The secondary antibody was the anti-mouse biotinylated antibody (Vectastain ${ }^{\circledR}$, Vector Laboratories, Inc., Burlingame, CA, USA). Antigen-antibody complexes were detected with 3,3'-diaminobenzidine. In all assays, positive (carcinoma of the esophagus) and negative (exclusion of primary antibody in reaction) controls were used.

Glass slides were examined under the light microscope. The criterion for a positive p53 immunoreaction was the presence of at least a group of immunostained cell nuclei (see Figure 1).

A total of 167 surgeries were performed on the 148 patients studied here $(60 \%$ females and $40 \%$ males, ranging in age from 16 to 76 years, mean 44.4 years). Fifteen patients underwent two surgeries and two patients were submitted to three surgeries. Nonfunctioning adenomas made up 35\% of cases, and the others were associated with endocrine hypersecretion syndrome of ACTH, GH and/or PRL. Sellar scans (computed tomography or magnetic resonance) were available for 125 patients. Of these, $104(83.2 \%$ of cases) presented macro- 
adenomas, 35 of which ( $28 \%$ of total) with invasive characteristics.

p53 protein was positive in $2 / 148$ patients $(1.3 \%)$. Immunohistochemistry revealed that both adenomas were GH- and PRL-producing. One of the patients was a 35 -year-old male with clinical acromegaly and PRL levels above 20,000 $\mathrm{ng} / \mathrm{ml}$. He presented a giant adenoma with invasion of the sphenoid and nasal fossae. The Ki-67 index of this adenoma (Oliveira MC, Pizarro CB, Barbosa-Coutinho LM and Ferreira NP, unpublished results) was $0.20 \%$. The patient died within a few months. The other patient was a 71-year-old female also with clinical acromegaly. The pituitary scan showed an intrasellar lesion with roof erosion. The Ki67 index of this adenoma was $0.36 \%$. Six years after surgery, the patient remains healthy.

Mean patient age and sex distribution were in agreement with the literature $(10,11)$, as also was the frequency of the different types of hormonal secretion (11). Most of the adenomas found were macroadenomas, and $28 \%$ of these were of the invasive type. The incidence of invasion by pituitary adenomas reported in the literature is high, ranging from 10 to $85 \%$ depending on the criterion used to define whether an adenoma is invasive or not. The index is much higher when microscopic invasion of the dura mater is considered.

Expression of p53 protein has seldom been studied in pituitary adenomas and different results were obtained in the available reports. A number of studies failed to detect p53 in adenomas and even in pituitary carcinomas $(5,6,10,12)$, while others detected the presence of the mutated protein $(7-9,13)$. The reasons for these discrepancies are unclear, but must be related to difficulties in the various steps of the immunohistochemical technique used, criteria for positive reaction, and characteristics of the material studied, which include small samples, coexistence of normal tissue in the middle of neo- plastic tissue, and heterogeneity concerning the function and characteristics of cell replication in each adenoma.

Sumi et al. (5) did not detect $\mathrm{p} 53$ protein in 40 adenomas of several hormonal phenotypes, of which 17 were recurrent and 3 were invasive. Gandour-Edwards et al. (6) did not detect the presence of p53 in 5 normal pituitary tissues and in 20 invasive and noninvasive adenomas. Lübke et al. (12), in a study of 19 ACTH-secreting adenomas only, obtained negative results, as also did Müller et al. (10). The latter group studied patients with acromegaly, 27 with plurihormonal adenomas and 21 with GH- and PRL-secreting adenomas. Immunohistochemistry for p53 was negative in all cases studied.

Buckley et al. (7) used three different antibodies to evaluate 121 adenomas of all functional classifications, of which 95 were benign and 26 presented local invasion or invasion over distance. The presence of $\mathrm{p} 53$ was detected in $16 \%$ of invasive tumors, but only in ACTH-secreting tumors (2/4) and in nonfunctioning tumors $(4 / 15)$.

Levy et al. (9) detected p53 in 5 of 29 noninvasive adenomas and Thapar's group (8), in a study of 70 adenomas and 7 pituitary adenocarcinomas, found p53 expression in 12 tumors. Among those with a positive reaction were all the adenocarcinomas and $15.2 \%$ of invasive adenomas. None of the noninvasive tumors was positive for $\mathrm{p} 53$. Thus, these investigators concluded that there is a significant association between expression of p53 and aggressive tumor behavior, with no connection with functional tumor state, indicating that expression of $\mathrm{p} 53$, though rare among pituitary tumors as a whole, appears to some extent in aggressive tumors, particularly in those with massive local invasion or dissemination at a distance. Suliman et al. (13) evaluated p53 expression in 40 pituitary adenomas and obtained positive results in 24 cases, while no correlation between positive immunoreaction and tumor volume or extent of invasion was observed. 
An analysis of the above data shows that findings are inconsistent and that positive reaction for $\mathrm{p} 53$, when detected, is restricted either to a given type of hormonal secretion (or to its absence) or to aggressiveness characteristics. The highest frequency of p53 immunoreaction in ACTH-secreting adenomas has not been clarified (14). Moreover, the percentage of positive results, even if it was significant within the unique subset in which it was found, was too low in relation to the whole sample studied.

The present series is the largest among those reviewed. Here p53 was detected in a very low percentage $(1.3 \%)$ of the total sample of 148 and in $5.7 \%$ of invasive adenomas. It is remarkable that in both cases of positive immunoreaction, concomitant secretion of GH and PRL by the tumor was observed. There is one study in the literature reporting a PRL-secreting adenoma, a GHsecreting adenoma, and a stem cell adenoma among five p53-positive adenomas found (8), and another study reporting a PRL-secreting adenoma and another one secreting $\mathrm{GH}+\mathrm{PRL}+\mathrm{ACTH}$ (9), but such findings are rare. Unlike Buckley's report (7), p53 was not detected in any of the nonfunctioning or ACTH-secreting adenomas, though Thapar et al. (8) suggested that there is no link between positive reaction for p53 and tumor functional profile.

The possible association between $\mathrm{p} 53$ detection and cell replication indices has not been explored in the literature. The Ki-67 index is a nuclear antigen expressed in proliferating cells during the $\mathrm{G} 1, \mathrm{~S}, \mathrm{G} 2$ and $\mathrm{M}$ phases of the cell cycle (15). Pituitary adenomas in general are associated with either absence of a positive reaction for $\mathrm{Ki}-67$ antigen or low levels of it, usually under $1 \%$. However, a significant difference has been established between invasive and noninvasive tumors. The mean Ki-67 index (in stud- ies using MIB-1 for detection of Ki-67 antigen in material embedded in paraffin) ranges from 0.15 (16) to 2.01 for noninvasive adenomas (11) and from 1.27 (17) to 4.66 for invasive adenomas (18). Our figures are 0.86 for microadenomas, 1.12 for macroadenomas with or without suprasellar extension, and 2.01 for invasive adenomas (Oliveira MC, Pizarro CB, Barbosa-Coutinho LM and Ferreira NP, unpublished data). Both patients with a positive reaction for $\mathrm{p} 53$ in this series were evaluated for Ki-67 index, showing low positive values of 0.2 and 0.36 . The small number of cases precludes correlating p53 with the Ki-67 index.

Concerning genomic alterations in p53, the data suggest that mutations are unusual events in pituitary tumorigenesis. It is well known that $90 \%$ of the mutations in TP53 occur in the region of exons 5 through 8 , but when evaluating these exons, no mutation was detected (19). However, immunohistochemistry alone is not a good method to predict TP 53 mutations detected by sequencing, because there is no adequate association between the results obtained by the two techniques (9), and accumulation of protein may coexist with a normal TP53 (20). In the literature, conclusions concerning the role of TP53 and the expression of its mutated protein in pituitary tumors are not in agreement, ranging from suggestions that these changes are not involved in tumorigenesis or in the progression and recurrence of tumors (5) to claims that p53 may play a role in tumor progression but not in tumor initiation (20). The findings reported here allow us to suggest that the presence of $\mathrm{p} 53$ protein is a rare event in pituitary adenomas that appears to be associated with invasion of adjacent structures, though there is no indication of its efficacy as a routine marker of tumor aggressiveness. 


\section{References}

1. Burrow GN, Wortzman G, Rewcastle NB, Holgate RC \& Kovacs K (1981). Microadenomas of the pituitary and abnormal sellar tomograms in an unselected autopsy series. New England J ournal of Medicine, 304: 156-158.

2. Elster AD (1993). Modern imaging of the pituitary. Radiology, 187: 1-14.

3. Asa SL \& Ezzat S (1998). The cytogenesis and pathogenesis of pituitary adenomas. Endocrine Reviews, 19: 798-827.

4. Harris C \& Hollstein M (1993). Clinical implications of the p53 tumor-suppressor gene. New England J ournal of Medicine, 329: 1318-1327.

5. Sumi T, Stefaneanu L, Kovacs K, Asa S \& Rindi G (1993). Immunohistochemical study of p53 protein in human and animal pituitary tumors. Endocrine Pathology, 4: 95-99.

6. Gandour-Edwards R, Kapadia SB, J anecka IP, Martinez AJ \& Barnes L (1995). Biologic markers of invasive pituitary adenomas involving the sphenoid sinus. Modem Pathology, 8: 160-164.

7. Buckley N, Bates AS, Broome J C, Strange RC, Perrett CW, Burke CW \& Clayton RN (1994). p53 protein accumulates in Cushing's adenomas and invasive non-functional adenomas. J ournal of Clinical Endocrinology and Metabolism, 79: 1513-1516.

8. Thapar K, Scheithauer BW, Kovacs K, Pernicone PJ \& Laws J r ER (1996). p53 expression in pituitary adenomas and carcinomas: correlation with invasiveness and tumor growth fractions. Neurosurgery, 38: 765-771.

9. Levy A, Hall L, Yeudall WA \& Lightman SL (1994). p53 gene mutations in pituitary adenomas: rare events. Clinical Endocrinology, 41: 809-814.

10. Müller W, Saeger W, Wellhausen L, Derwahl KM, Hamacher C \& Ludecke DK (1999). Markers of function and proliferation in non-invasive and invasive bi- and plurihormonal adenomas of patients with acromegaly: an immunohistochemical study. Pathology, Research and Practice, 195: 595-603.

11. Mastronardi L, Guiducci A, Spera C, Puzzilli F, Liberati F \& Maira G (1999). Ki67 labelling index and invasiveness among anterior pituitary adenomas: analysis of 103 cases using the MIB-1 monoclonal antibody. J ournal of Clinical Pathology, 52: 107-111.

12. Lübke D, Saeger W \& Lüdecke DK (1995). Proliferation markers and EGF in ACTHsecreting adenomas and carcinomas of the pituitary. Endocrine Pathology, 5: 4555.

13. Suliman M, Royds J, Cullen D, Timperley W, Powell $T$, Battersby $R \&$ J ones $T H$ (2000). Markers of pituitary adenoma invasiveness. Pituitary, 3: 19 (Abstract OC11).

14. Clayton RN, Boggild M, Bates AS, Bicknell J , Simpson D \& Farrell W (1997). Tumour suppressor genes in the pathogenesis of human pituitary tumours. Hormone Re- search, 47: 185-193.

15. Gerdes J , Schwab U, Lemke H \& Stein H (1983). Production of a mouse monoclonal antibody reactive with a human nuclear antigen associated with cell proliferation. International J ournal of Cancer, 31: 13-20.

16. Atkin SL, Green VL, Hipkin LJ, Landolt $A M$, Foy PM, J effreys RV \& White MC (1997). A comparison of proliferation indices in human anterior pituitary adenomas using formalin-fixed tissue and in vitro cell culture. J ournal of Neurosurgery, 87: 8588.

17. Mizoue T, Kawamoto H, Arita K, Kurisu K, Tominaga A \& Uozumi T (1997). MIB1 immunopositivity is associated with rapid regrowth of pituitary adenomas. Acta Neurochirurgica, 139: 426-432.

18. Thapar K, Kovacs K, Scheithauer BW, Stefaneanu L, Horvath E, Pernicone PJ , Murray D \& Laws ER (1996). Proliferative activity and invasiveness among pituitary adenomas and carcinomas: an analysis using the MIB-1 antibody. Neurosurgery, 38: 99-107.

19. Copelli SB, Loza Coll MA \& Bruno OD (1999). Absence of mutations in the p53 tumor suppressor gene in non-invasive Cushing adenomas. Medicine, 59: 459462.

20. Suhardja AS, Kovacs KT \& Rutka J T (1999). Molecular pathogenesis of pituitary adenomas: a review. Acta Neurochirurgica, 141: 729-736. 